\title{
Combined effects of octreotide and cisplatin on the proliferation of side population cells from anaplastic thyroid cancer cell lines
}

\author{
ZHILAN LI $^{1}$, XIUDI JIANG ${ }^{1}$, PEIHONG CHEN ${ }^{1}$, XUEBING WU $^{2}$, AIHUA DUAN $^{1}$ and YIYU QIN ${ }^{3}$ \\ Departments of ${ }^{1}$ Clinical Laboratory and ${ }^{2}$ Blood Transfusion, The Seventh People's Hospital of Shanghai, Shanghai 200137; \\ ${ }^{3}$ Research Centre of Biomedical Technology, Clinic Medical College, Jiangsu Vocational College of Medicine, \\ Yancheng, Jiangsu 224005, P.R. China
}

Received February 24, 2016; Accepted July 20, 2017

DOI: 10.3892/ol.2018.9105

\begin{abstract}
Anaplastic thyroid cancer(ATC) represents the most aggressive subtype of thyroid cancer and has a poor prognosis. In addition to surgery, chemotherapy is an important treatment for ATC; however, the therapeutic effects of current chemotherapies for ATC are not particularly promising. There is a high proportion of side population (SP) cells in ATC, which may be a reason for its drug resistance. In the present study, the antitumor activities of combined octreotide (OCT) and cisplatin (DDP) on the proliferation and apoptosis of ATC SP cells were evaluated. First, SP cells from 8305C and BHT101 cell lines were detected and sorted. Following in vitro culture for 1 week, cluster of differentiation (CD)44, CD133, ATP-binding cassette (ABC) subfamily $B$ member 1 (ABCB1), ABC subfamily $\mathrm{G}$ member 2 (ABCG2) and somatostatin receptor expression was detected to characterize the SP cells. An MTT assay was performed to investigate the combined effects on 8305C-SP cell proliferation in vitro, and a mouse model was used to investigate the combined effects on 8305C-SP cell proliferation in vivo. Annexin $\mathrm{V} /$ propidium iodide staining was used to investigate the combined effects on $8305 \mathrm{C}-\mathrm{SP}$ cell apoptosis. Chemotherapeutic drug resistance-associated protein expression and apoptosis-associated protein expression were also detected following combined treatment. As a result, SP cells were identified in $8305 \mathrm{C}$ and BHT101 cells, and the proportion of $8305 \mathrm{C}$-SP cells was increased compared with that of BTH101-SP cells. SP cells have enhanced proliferation, tumorigenicity and drug resistance compared with
\end{abstract}

Correspondence to: Dr Yiyu Qin, Research Centre of Biomedical Technology, Clinic Medical College, Jiangsu Vocational College of Medicine, 263 South Jiefang Road, Yancheng, Jiangsu 224005, P.R. China

E-mail: qinyiyu128@163.com

Dr Zhilan Li, Department of Clinical Laboratory, The Seventh People's Hospital of Shanghai, 358 Datong Road, Shanghai 200137, P.R. China

E-mail: lanlizhi1981@163.com

Key words: octreotide, cisplatin, thyroid carcinoma, side population main population cells. The combined treatment of OCT with DDP suppressed the proliferation of $8305 \mathrm{C}$-SP cells in vitro and in vivo, and induced $8305 \mathrm{C}-\mathrm{SP}$ cell apoptosis. Combined treatment decreased the ABCB1 and ABCG2 expression by SP cells and activated mitochondrial apoptotic signaling, resulting in cell apoptosis. In conclusion, these data support the hypothesis that combined treatment with OCT and DDP induces ATC cell apoptosis and suppresses cell proliferation. These data provide a theoretical basis for further combined chemotherapy clinical applications.

\section{Introduction}

Thyroid carcinoma is classified into papillary, follicular, medullary and anaplastic thyroid carcinoma (ATC) according to pathological and histological characterizations. ATC is the most aggressive type of thyroid cancer, although the proportion of ATC is only between 1 and 5\% of all thyroid cancers. ATC has a lethal and relentless clinical course with rapid progression and dissemination $(1,2)$. The majority of patients with ATC present with a rapidly growing thyroid mass, distinct distant metastases and a survival time of a few months $(3,4)$. Owing to the poor prognosis, the treatment of ATC is disappointing and ineffective. Local ATC is resected using surgical management, and subsequently, radiotherapy and systemic chemotherapy are used to restrain the residual neoplasm and distant metastases. A combination of these therapies is able to partially preclude the progression of ATC and prolong the lives of patients. Doxorubicin, cisplatin (DDP), 5-fluorouracil and paclitaxel are common chemotherapeutic agents for ATC. However, the therapeutic effects of standard chemotherapies for ATC are not particularly promising. Since chemotherapeutic agents in ATC are relatively ineffective, there may be one or more cellular mechanisms associated with chemotherapy resistance, which remain unclear $(5,6)$. A number of studies have suggested that the expression of multidrug resistance-associated proteins, which pump chemotherapy agents out of cells, results in resistance to chemotherapy $(1,7,8)$.

Cancer stem cells (CSCs) represent a small subset of stem-like cells within the bulk of the tumor, which possess the ability to self-renew and differentiate into diverse cancer cells. CSCs have been shown to be more aggressive and invasive, even more capable of resisting conventional therapies 
compared with other cancer cell types thus leading to drug resistance and relapse following treatment (9). CSCs were initially identified in acute myeloid leukemia and isolated in several other types of solid cancer. Such stem-like cells have been demonstrated to exist in thyroid cancer $(10,11)$. Furthermore, the specific expression levels of CSC markers, including aldehyde dehydrogenase (ALDH)1, cluster of differentiation (CD)133 and sex-determining region Y-box 2, along with chemotherapeutic resistance-associated proteins, including P-glycoprotein 1, multidrug resistance-associated protein-1 and lung resistance protein-1, are increased in ATC compared with in papillary thyroid carcinoma (12-14). These studies demonstrated that the increased number of CSCs within ATC compared with differentiated thyroid carcinoma may be the reason that ATC is more aggressive and drug-resistant than other subtypes.

However, the majority of tissue-restricted CSCs lack unique and specific expression markers to identify and isolate them. Goodell (15) identified and purified murine hematopoietic stem cells, termed side population (SP) cells, using flow cytometric analysis. SP cells are a small stem-like subset distinguished from main population (MP) cells, which have the ability to exclude the DNA-binding dye Hoechst 33342 . SP cells have been identified in numerous types of human and murine normal tissues, including bone marrow, skeletal muscle and the nervous system. Recently, SP cells have also been isolated in human breast cancer, lung cancer and glioblastoma cell lines and identified to contain CSCs (16-19). It has been shown that stem-like cell markers, including ATP-binding cassette (ABC) transporters such as ABC subfamily $G$ member 2 (ABCG2; also termed breast cancer-resistant protein-1), that are associated with multidrug resistance are overexpressed in SP cells (20). ABCG2 is a membrane protein that pumps chemotherapeutic drugs out of cells (21). In addition, SP cells have aggressive tumorigenic, invasive and metastatic abilities. Currently, there are no specific and sensitive CSC molecular markers, and SP cells remain an important choice to identify and isolate CSCs. In the present study, SP cells were sorted from the ATC 8305C and BHT101 cell lines and the SP cells were characterized. The effects of a combination of OCT and DDP on the proliferation and apoptosis of SP cells were also investigated.

\section{Materials and methods}

Reagents. The reagents used were as follows: Octreotide (OCT; Novartis International AG, Basel, Switzerland), Hoechst 33342 (Invitrogen; Thermo Fisher Scientific, Inc., Waltham, MA, USA), verapamil (Sigma-Aldrich; Merck KGaA, Darmstadt, Germany) and MTT (Sigma-Aldrich; Merck KGaA). The antibodies used were bought from Santa Cruz Biotechnology, Inc. (Dallas, TX, USA).

Cell culture. The human ATC BHT101 (22) and 8305C (23) cell lines were obtained from the Type Culture Collection of the Chinese Academy of Sciences (Shanghai, China) and cultured in Dulbecco's modified Eagle's medium (Gibco; Thermo Fisher Scientific, Inc.) containing 10\% fetal bovine serum (HyClone; GE Healthcare Life Sciences, Logan, UT, USA) and $1 \%$ penicillin/streptomycin (Sigma-Aldrich; Merck
$\mathrm{KGaA}$ ). Cells were maintained at $37^{\circ} \mathrm{C}$ in a humidified atmosphere containing $5 \% \mathrm{CO}_{2}$. Culture medium was changed daily.

Flow cytometry for SP cells. BHT101 and 8305C cells in the exponential phase were collected and detached by $0.25 \%$ trypsinization and resuspended at a density of $1 \times 10^{6} \mathrm{cells} / \mathrm{ml}$. Cells were labeled in the growth medium with $5 \mu \mathrm{g} / \mathrm{ml}$ Hoechst 33342 either alone or in combination with $100 \mu \mathrm{g} / \mathrm{ml}$ verapamil in the dark for $90 \mathrm{~min}$ at $37^{\circ} \mathrm{C}$. Cells were vortex-mixed gently every 15 min during the incubation. Following washing by phosphate buffer saline (PBS), the cell suspension was centrifuged at $500 \mathrm{xg}$ for $5 \mathrm{~min}$ at $4^{\circ} \mathrm{C}$ and the supernatant was removed, followed by adding $1 \mu \mathrm{g} / \mathrm{ml}$ propidium iodide into the resuspension. SP analysis and sorting were performed using fluorescence-activated cell sorting. The Hoechst dye was excited with $350 \mathrm{~nm}$ and its fluorescence was measured with 675/20 nm (Hoechst red) and 450/30 nm (Hoechst blue) filters. The cells with Hoechst 33342 low or negative fluorescence were considered to be the SP cells. Analysis was performed using a BD FACSAria II FACS sorter (BD Biosciences, Franklin Lakes, NJ, USA) and the data were analyzed by BD FACSDiva Software.

Identification of SP cells. Sorted SP and MP cells were seeded on 6-well plates at a concentration of $1 \times 10^{5} /$ well and incubated for 1 week at $37^{\circ} \mathrm{C}$ and $5 \% \mathrm{CO}_{2}$. The protein levels of CSC-associated markers, including ALDH, CD44, CD133, $\mathrm{ABCG} 2$ and $\mathrm{ABCB} 1$ in SP and MP cells were detected using associated antibodies via western blotting.

Western blotting. Sorted or treated cells were collected and washed with ice-cold PBS twice. A whole-cell protein extraction kit (Novagen; EMD Millipore, Billerica, MA, USA) was used to extract the cell protein, according to the manufacturer's protocol. Cell lysates were clarified by centrifugation at $12,000 \mathrm{x} \mathrm{g}$ for $10 \mathrm{~min}$ at $4^{\circ} \mathrm{C}$ and the supernatants were mixed with $5 \mathrm{X}$ loading dye and boiled for $10 \mathrm{~min}$. The protein contents in the supernatant were measured by the Bradford assay. A total of $30 \mu \mathrm{g}$ proteins were separated by SDS-PAGE (10\% gels) and electrotransferred onto a polyvinylidene fluoride membrane (EMD Millipore). The membrane was blocked in 5\% non-fat skimmed milk for $1 \mathrm{~h}$ at room temperature and probed with primary antibodies at $4^{\circ} \mathrm{C}$ overnight followed by incubation with horseradish peroxidase-conjugated secondary antibodies. Protein expression was detected using an enhanced chemiluminescence system (Beyotime Institute of Biotechnology, Haimen, China). GAPDH and cytochrome $c$ oxidase subunit IV (COX IV) were used as internal controls for cytoplasmic and mitochondrial proteins. The primary antibodies used were listed as follows: GAPDH monoclonal antibody (cat. no. sc-166574; Santa Cruz Biotechnology, Inc.; 1:100; $4^{\circ} \mathrm{C}$ overnight), CD133 monoclonal antibody (cat no. MA5-18323; Invitrogen; Thermo Fisher Scientific, Inc.; $1: 500 ; 4^{\circ} \mathrm{C}$ overnight), CD34 monoclonal antibody (cat no. MA5-13890; Invitrogen; Thermo Fisher Scientific, Inc.; $2 \mu \mathrm{g} / \mathrm{ml} ; 4^{\circ} \mathrm{C}$ overnight), ABCG 2 monoclonal antibody (cat no. sc-18841; Santa Cruz Biotechnology, Inc.; 1:200; $4^{\circ} \mathrm{C}$ overnight), ALDH monoclonal antibody (cat no. MA5-15692; Invitrogen; Thermo Fisher Scientific, Inc.; 1:500; $4^{\circ} \mathrm{C}$ 
A
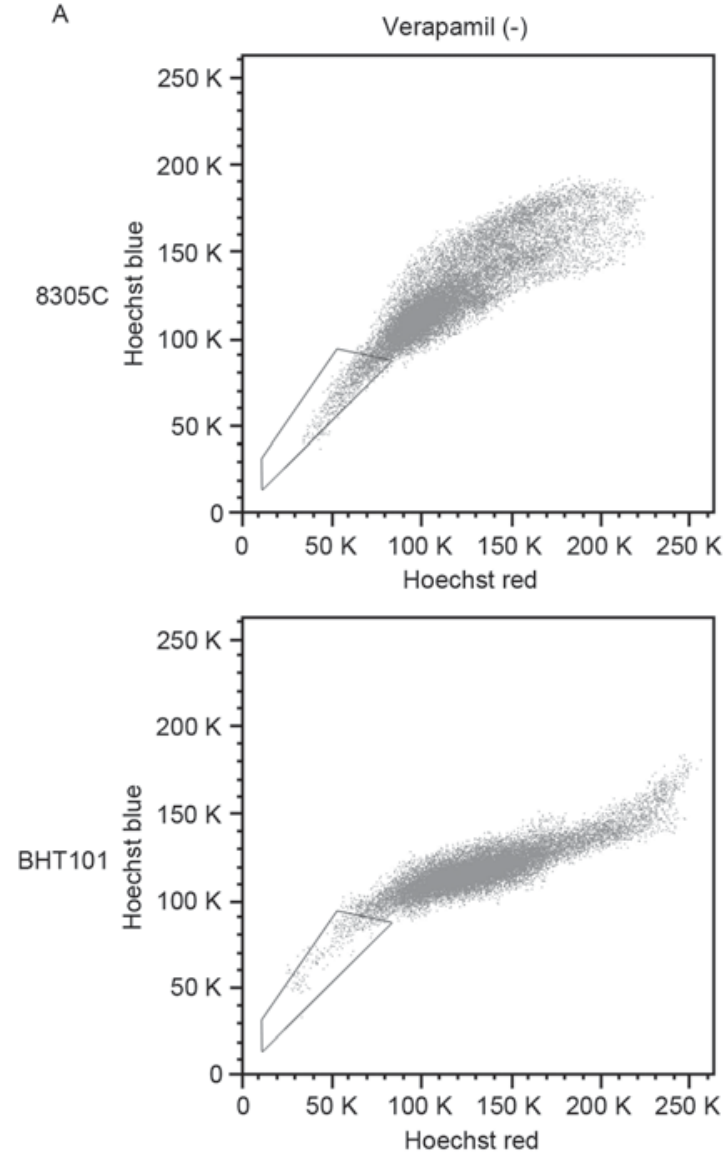

B

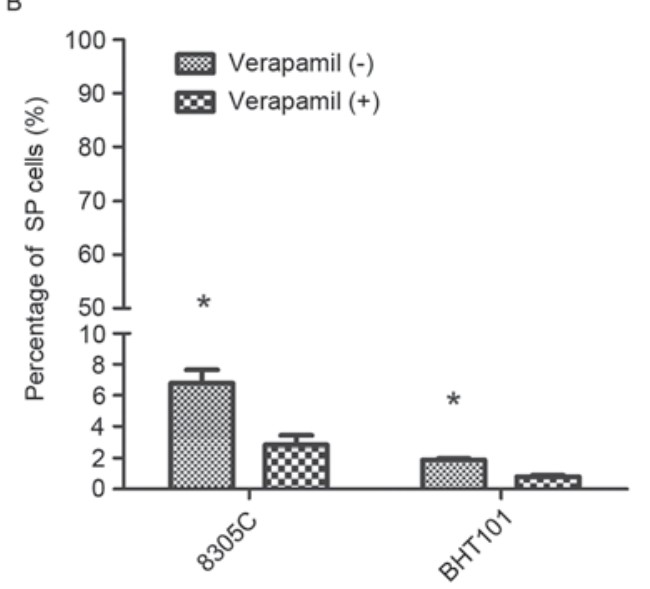

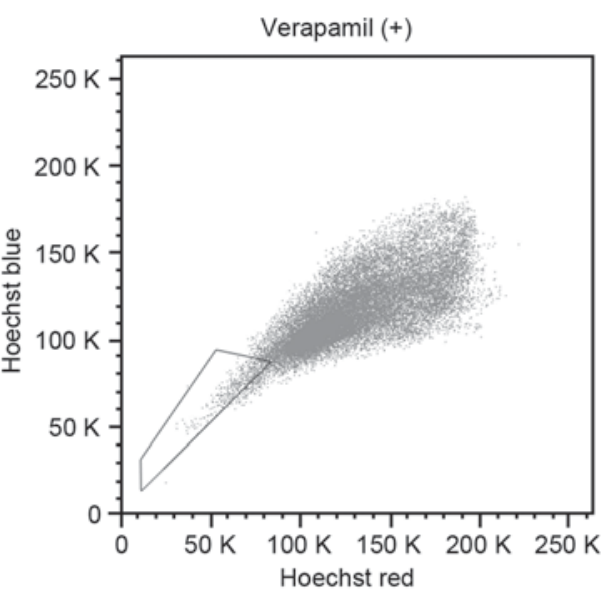

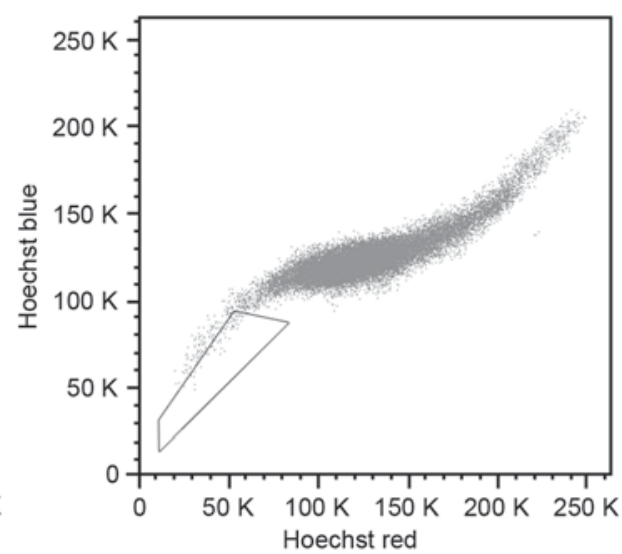

C

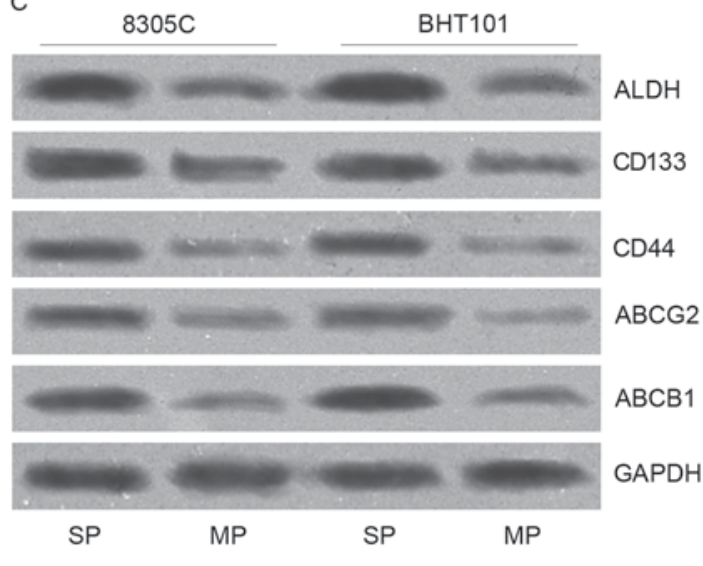

Figure 1. Identification and isolation of SP cells from human anaplastic thyroid cancer BHT101 and 8305C cell lines. (A) Treatment of Hoechst 33342 dye followed by flow cytometric analysis separated the SP cells from MP cells, which are represented in the box. (B) BHT101 and 8305C cells were labeled with $5 \mu \mathrm{g} / \mathrm{ml}$ Hoechst 33342 either alone or in combination with $100 \mu \mathrm{g} / \mathrm{ml}$ verapamil. The proportion of SP cells was analyzed by flow cytometry. "P $<0.05$. (C) Protein level of cancer stem cell-associated markers in 8305C-SP and 8305C-MP cells. SP, side population; MP, main population; ALDH, aldehyde dehydrogenase; $\mathrm{CD}$, cluster of differentiation; ABCG2, ATP-binding cassette subfamily G member 2; ABCB1, ATP-binding cassette subfamily B member 1 .

overnight), ABCB1 monoclonal antibody (cat no. MA5-13854; Invitrogen; Thermo Fisher Scientific, Inc.; 1:200; $4^{\circ} \mathrm{C}$ overnight), Bcl-2-associated $\mathrm{X}$ protein monoclonal antibody (cat no. MA5-14003; Invitrogen; Thermo Fisher Scientific, Inc.; $1: 50 ; 4^{\circ} \mathrm{C}$ overnight), B cell lymphoma-2 (Bcl-2) monoclonal antibody (cat no. MA5-11757; Invitrogen; Thermo Fisher Scientific, Inc.; $2 \mu \mathrm{g} / \mathrm{ml} ; 4^{\circ} \mathrm{C}$ overnight), Cytochrome C monoclonal antibody (cat no. sc-13561; Santa Cruz Biotechnology, Inc.; $1: 200 ; 4^{\circ} \mathrm{C}$ overnight), Caspase- 3 monoclonal antibody (cat no. sc-1225; Santa Cruz Biotechnology, Inc.; 1:200; $4^{\circ} \mathrm{C}$ overnight), cleaved poly(ADP-ribose) polymerase polyclonal antibody (cat no. sc-23461-R; Santa Cruz Biotechnology, Inc.; $1: 200 ; 4^{\circ} \mathrm{C}$ overnight), COX IV monoclonal antibody (cat no. sc-376731; Santa Cruz Biotechnology, Inc.; 1:100, $4^{\circ} \mathrm{C}$ overnight), somatostatin receptor (SSTR) 1 monoclonal antibody (cat no. sc-293490; Santa Cruz Biotechnology, Inc.; $1: 100 ; 4^{\circ} \mathrm{C}$ overnight), SSTR 2 monoclonal antibody (cat no. sc-365502; Santa Cruz Biotechnology, Inc.; 1:100; $4^{\circ} \mathrm{C}$ overnight), SSTR3 polyclonal antibody (cat no. PA3-110; Invitrogen; Thermo Fisher Scientific, Inc.; 1:5,000; $4^{\circ} \mathrm{C}$ 
A

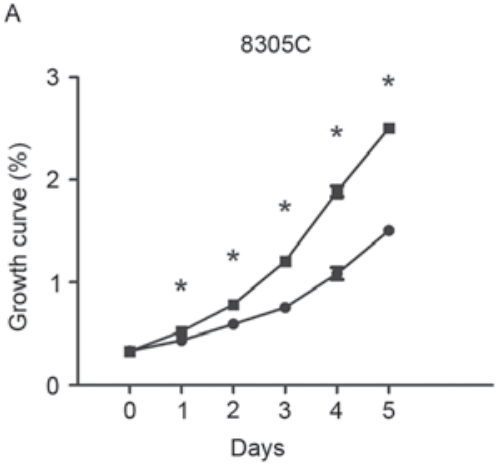

C

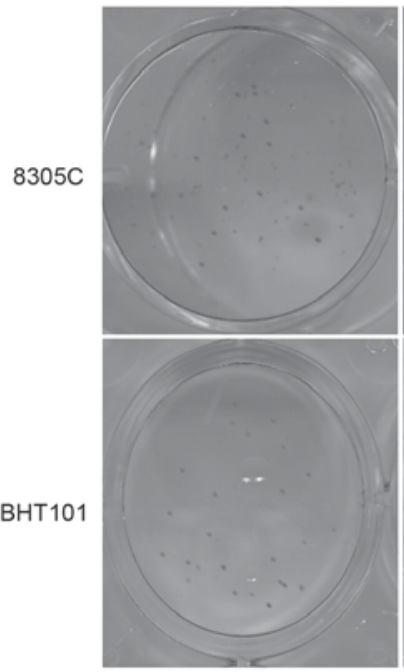

E

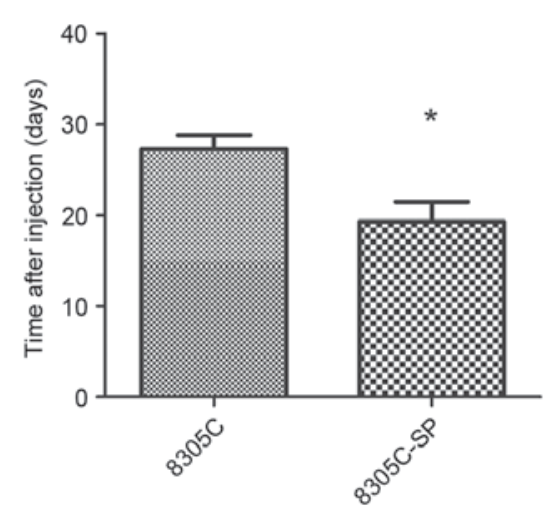

SP

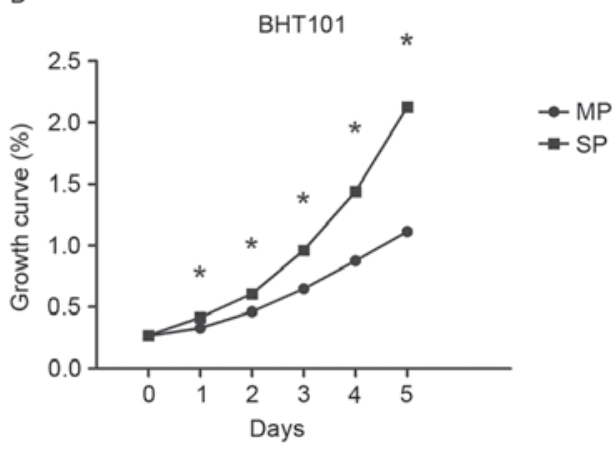

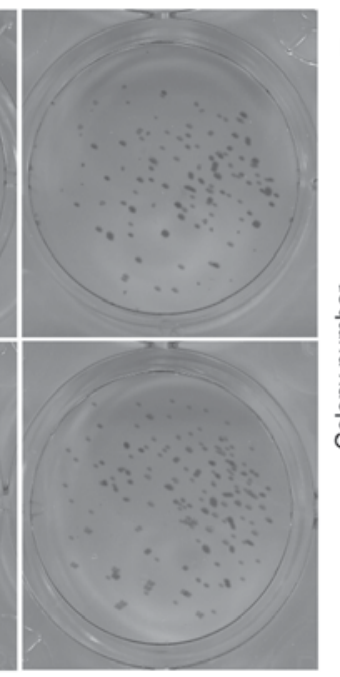

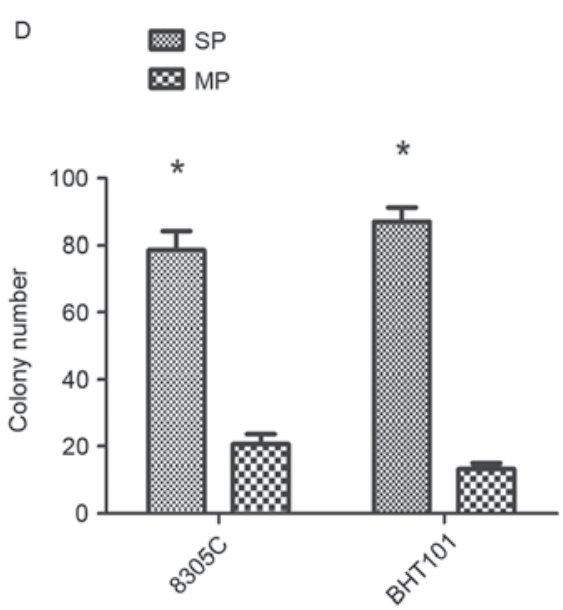

$\mathrm{F}$

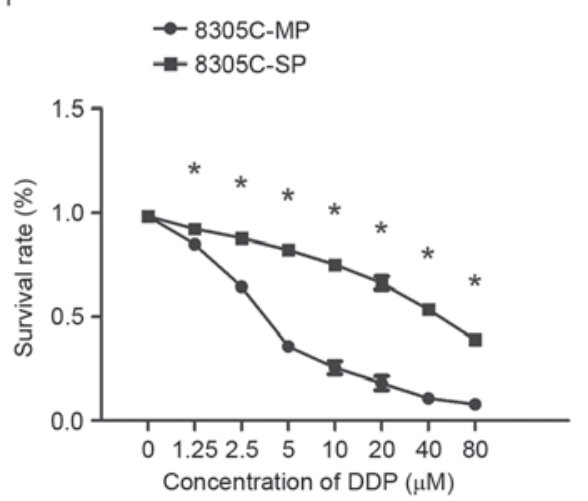

Figure 2. Biological characterization of $8305 \mathrm{C}-\mathrm{SP}$ cells. (A) Proliferation rates of 8305C-SP and 8305C-MP cells determined using the MTT assay at 0, 24, 48, 72,96 and $120 \mathrm{~h}$. (B) Proliferation rates of BHT101-SP and BHT101-MP cells determined using the MTT assay at 0, 24, 48, 72, 96 and $120 \mathrm{~h}$. Colony formation ability of SP and MP cells: (C) Colony formation was stained with Giemsa following culture for 14 days; (D) numbers of colonies formed in each well were counted using a microscope. Plating efficiency=(colony numbers/initial cell numbers) $x 100 \%$. (E) Mean time for xenograft formation. (F) Drug resistance to DDP was detected according to the inhibition of cell proliferation. Data are presented as the mean \pm standard deviation. ${ }^{*} \mathrm{P}<0.05$ (one-way analysis of variance). SP, side population; MP, main population; DDP, cisplatin.

overnight), SSTR4 polyclonal antibody (cat no. PA3-111; Invitrogen; Thermo Fisher Scientific, Inc.; 1:500; $4^{\circ} \mathrm{C}$ overnight), SSTR5 polyclonal antibody (cat no. PA3-112; Invitrogen; Thermo Fisher Scientific, Inc.; 1:5,000; $4^{\circ} \mathrm{C}$ overnight), goat anti-mouse immunoglobulin $\mathrm{G}$ (IgG) horseradish peroxidase (HRP)-conjugated (cat no. sc-2005; Santa Cruz Biotechnology, Inc.; $1: 2,000 ; 25^{\circ} \mathrm{C}, 1 \mathrm{~h}$ ) and goat anti-rabbit IgG-HRP (cat no. sc-2004; Santa Cruz Biotechnology, Inc.; $\left.1: 5,000 ; 25^{\circ} \mathrm{C}, 1 \mathrm{~h}\right)$
Cell proliferation assay. Cell proliferation was detected using an MTT assay. Sorted and cultured SP and MP cells were detached by $0.25 \%$ trypsinization, resuspended and seeded at a density of $2 \times 10^{3}$ cells/well on 96 -well plates. Following incubation for 1, 2, 3, 4 and 5 days, $10 \mu 1$ MTT (5 mg/ml final concentration) was added to each well. Following incubation at $37^{\circ} \mathrm{C}$ for $4 \mathrm{~h}, 100 \mu \mathrm{l}$ dimethyl sulfoxide was added to each well. The plate was rocked gently in the dark for $\sim 10$ min until the blue sedimentation crystals were completely dissolved. 

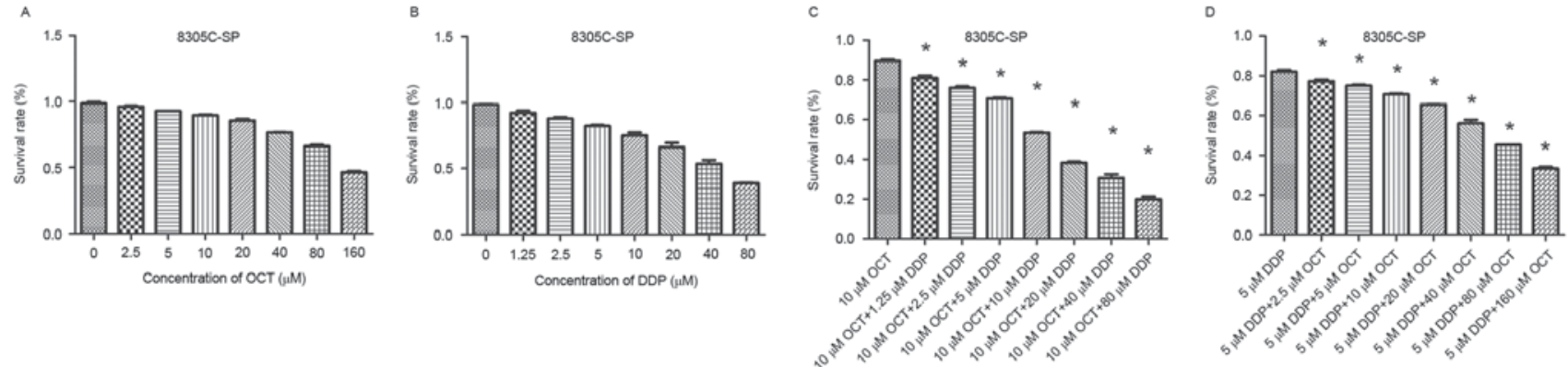

E
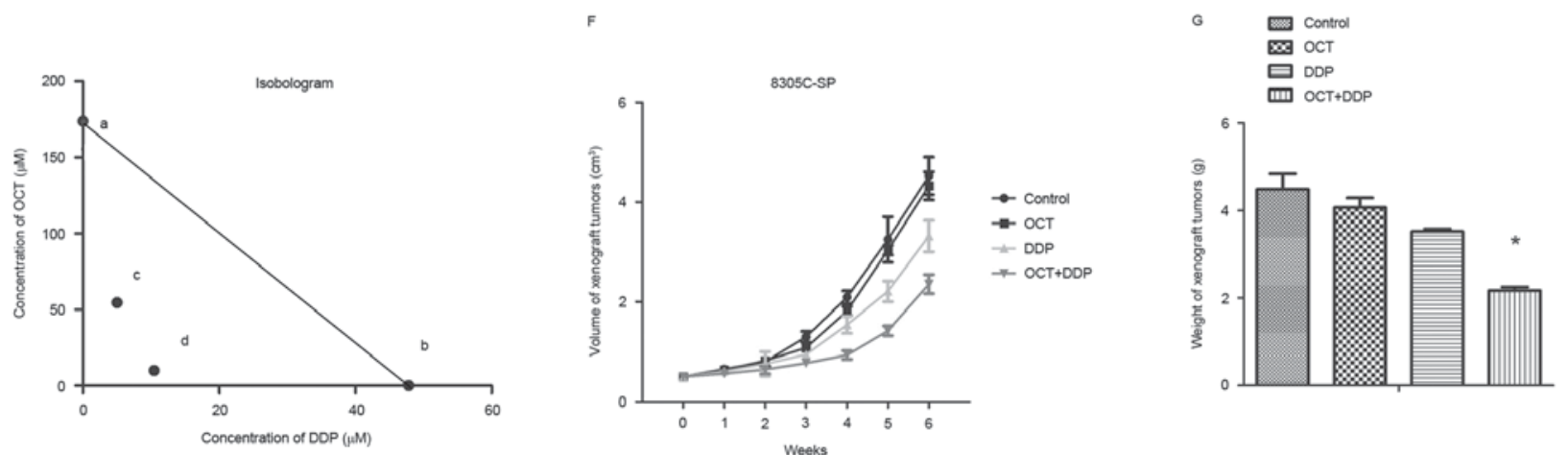

Figure 3. Synergistic effect of OCT and DDP on 8305C-SP cell proliferation inhibition. (A) 8305C-SP cell proliferation rates at different concentrations of OCT. (B) $8305 \mathrm{C}$-SP cell proliferation rates at different concentrations of DDP. (C) $8305 \mathrm{C}$-SP cell proliferation rates at $10 \mu \mathrm{M}$ OCT in combination with different concentrations of DDP. (D) 8305C-SP cell proliferation rates at $5 \mu \mathrm{M}$ DDP in combination with different concentrations of OCT. (E) Isobologram analysis of the combination effect of OCT and DDP. First, it was assumed that the individual $\mathrm{IC}_{50}$ values of OCT and DDP were a (0, 173.8) and b (47.83, 0) in the coordinate axis, which were able to align into a straight line as ab. Next, two new $\mathrm{IC}_{50}$ values, c $(5,54.58)$ and $\mathrm{d}(10.44$, 10$)$, were obtained following combination treatment and cd was aligned into a new straight line. If cd coincides with ab, then these two drugs do not interfere with each other. If cd is located above $\mathrm{ab}$, these two drugs are antergic. If cd is located below ab, these two drugs are synergetic. OCT and DDP interaction belonged to the third type, so their combined effect is synergy. $(\mathrm{F})$ The volume of mice tumor was determined with the treatment of OCT and/or DDP. (G) The weight of each tumor mass after 25 days. "P<0.05 (one-way analysis of variance). OCT, octreotide; DDP, cisplatin; SP, side population; IC $_{50}$, half-maximal inhibitory concentration.

Finally, $200 \mu$ l each sample was transferred to another 96-well plate and the absorbance was determined on a microplate reader at $570 \mathrm{~nm}$. Each treatment was performed in triplicate.

Isobologram analysis. To evaluate the combined effects of OCT and DDP, the isobologram method of Steel and Peckham was used (24). Briefly, the half-maximal inhibitory concentrations ( $\mathrm{IC}_{50}$ values) of OCT and $\mathrm{IC}_{50}$ of DDP are presented as ' $\mathrm{a}$ ' $\left(0, \mathrm{IC}_{50}\right.$ of OCT) and 'b' $\left(\mathrm{IC}_{50}\right.$ of DDP, 0$)$ in a two-coordinate plot, and the line of additivity was constructed by connecting the two points. The new IC50 of OCT combined with $5 \mu \mathrm{M}$ DDP was calculated and designated as 'c', and the new IC50 of DDP combined with $20 \mu \mathrm{M}$ OCT was calculated and designated as ' $d$ '. Points ' $c$ ' and ' $d$ ' below, at, and above the isobologram line for a given effect level were considered to indicate synergy, additive effect and antagonism, respectively.

Drug resistance assay. SP and MP cells were seeded at a density of $5 \times 10^{3}$ cells/well on 96 -well plates. After $24 \mathrm{~h}$, culture medium was replaced. DDP $(0,1.25,2.5,5,10,20,40$ and $80 \mu \mathrm{M})$ and $\mathrm{OCT}(0,2.5,5,10,20,40,80$ and $160 \mu \mathrm{M})$ were added to the medium at various concentrations. Cell viability was determined following incubation using the MTT assay as aforementioned.

Colony formation assay. SP and MP cell suspension was added to a 12 -well plate at a concentration of 50 cells per well. The colony formation was stained after 14 days of culture using Giemsa at room temperature for $20 \mathrm{~min}$. The numbers of colonies formed in each well were counted using an Olympus BX53 fluorescence microscope (Olympus Corporation, Tokyo, Japan) with a magnification of up to x100. Results were calculated using the following formula: Plating efficiency $=$ (colony numbers/initial cell numbers) $\times 100 \%$.

Cellapoptosis assay. An Annexin V-Fluorescein Isothiocyanate (FITC) Apoptosis Detection kit (BD Biosciences) was used to evaluate the proportion of apoptotic cells, according to the manufacturer's protocol. SP cells were treated with OCT (10 and $40 \mu \mathrm{M})$ and DDP $(5$ and $20 \mu \mathrm{M})$ alone or combined. A total of $5 \times 10^{5}$ treated cells were centrifuged at $1,000 \times \mathrm{g}$ for $5 \mathrm{~min}$ at room temperature followed by washing with ice-cold PBS. Cells were resuspended in ice-cold $1 \mathrm{x}$ binding buffer (included in the kit) and annexin V-FITC was added for 30 min incubation at room temperature in the dark. Subsequently, propidium iodide (PI) was added, and the suspension was analyzed using a BD FACSAria II FACS sorter (BD Biosciences).

Xenograft mouse model. All animal experiments were approved and conducted by the Institutional Animal Care and Use Committee of The Seventh People's Hospital of Shanghai (Shanghai, China). The 8305C-SP and 8305C-MP cells were resuspended in growth medium. A total of 48 female BALB/c nude mice 4-6-weeks-old [weight, 20-25 g; housed in a temperature $\left(21^{\circ} \mathrm{C}\right)$ and humidity $(50 \%)$ controlled environment with a $12 \mathrm{~h}$ light/dark cycle in specific pathogen-free 

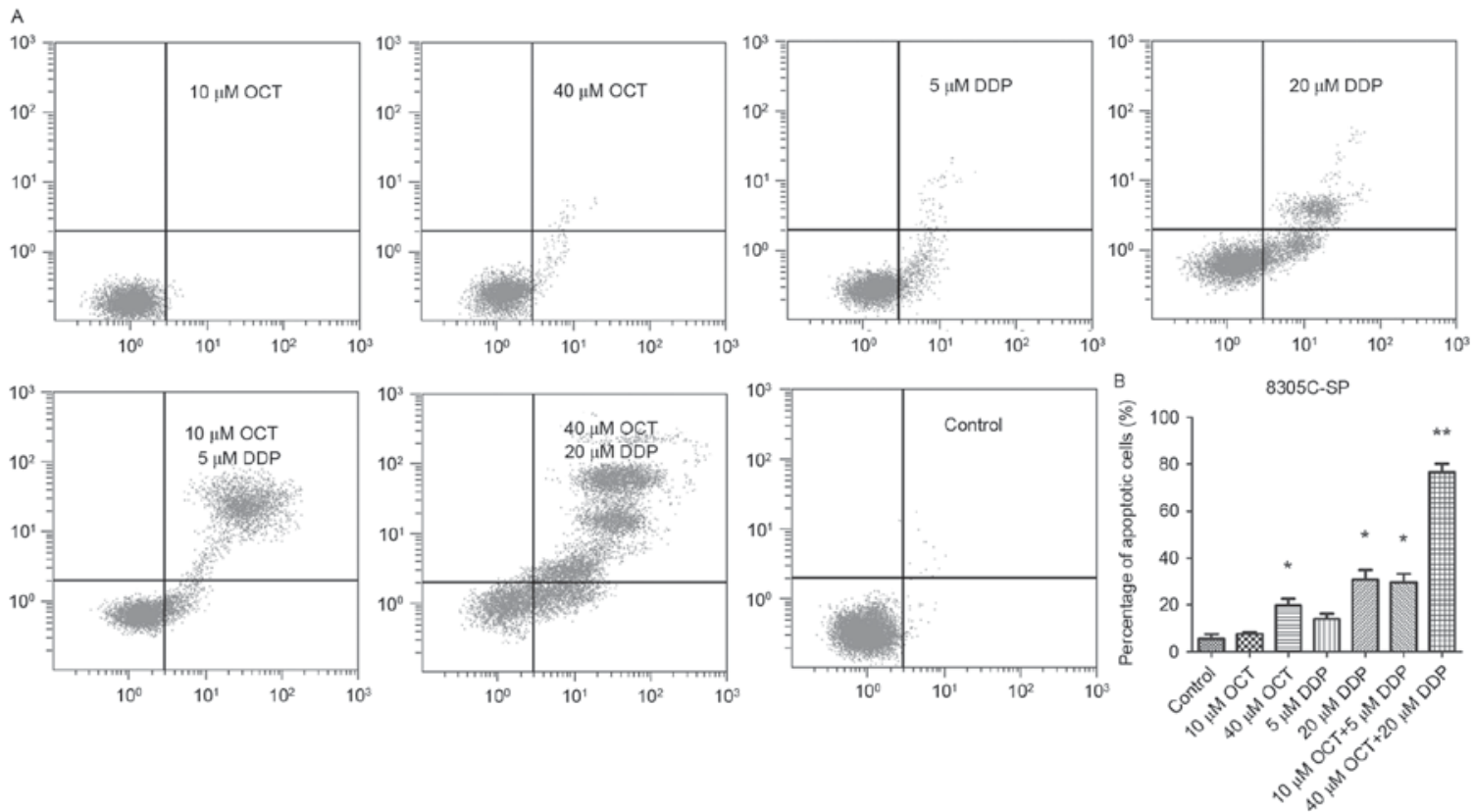

Figure 4. Combined induction of 8305C-SP cell apoptosis by OCT and DDP. (A) Apoptosis induced by different treatments was detected by flow cytometry. Living cells are in the left lower quadrant, early-stage apoptotic cells are in the right lower quadrant and late-stage apoptotic cells are in the right upper quadrant. (B) Proportion of apoptotic $8305 \mathrm{C}-\mathrm{SP}$ cells. " $\mathrm{P}<0.05 ;{ }^{* *} \mathrm{P}<0.01$ (one-way analysis of variance) vs./the control. OCT, octreotide; DDP, cisplatin; SP, side population.

conditions and ad libitum access to standard food and water] were randomly divided into each group (6 mice/group) and subcutaneously injected with $5 \times 10^{6}$ cell suspension. To test the tumorigenicity of SP cells, three animal groups were designed: 8305C $(n=6), 8305-\mathrm{SP}(\mathrm{n}=6)$ and 8305-MP $(\mathrm{n}=6)$ cells. To test the antitumor activities of OCT and DPP, four animal groups were designed: OCT $(n=6)$, DPP $(n=6)$, OCT+DDP $(n=6)$ and control $(n=6)$. The volume of each tumor mass was measured. To evaluate the combined effects of OCT and DDP on tumor growth in vivo, these two drugs were intraperitoneally injected when the tumor volume was $>0.5 \mathrm{~cm}^{3}$. OCT was injected at a dose of $100 \mu \mathrm{g} / \mathrm{kg}$ every day for 10 days. DDP was injected at a dose of $5 \mathrm{mg} / \mathrm{kg}$ every week for 4 weeks. The tumor volume was measured every 5 days. Tumor volume was calculated using the following formula: Volume=length $\mathrm{x}$ width $2 / 2\left(\mathrm{~cm}^{3}\right)$. The weight of each tumor mass was measured after mice were sacrificed 25 days later.

Statistical analysis. All statistical analyses were performed using SPSS version 14.0 (SPSS, Inc., Chicago, IL, USA). Results are presented as a ratio \pm standard deviation of the control. Student's t-test and one-way analysis of variance and Least Significant Difference post-hoc test were used to analyze the statistical significance. $\mathrm{P}<0.05$ was considered to indicate a statistically significant difference. Each experiment was performed in triplicate.

\section{Results}

Proportion of SP cells is increased in the 8305C cell line compared with in the BHT101 cell line. Hoechst 33342 dye was used to distinguish the SP cells from the MP human ATC cells (Fig. 1A). The results of flow cytometry revealed that there were $6.78 \pm 0.87 \%$ SP cells within $8305 \mathrm{C}$ cells and
$1.88 \pm 0.09 \%$ SP cells within the BHT101 cell line (Fig. 1B). Addition of verapamil decreased the SP proportion in $8305 \mathrm{C}$ $(2.81 \pm 0.60 \%)$ and BHT101 $(0.80 \pm 0.09 \%)$ cells. The SP proportion in $8305 \mathrm{C}$ cells was notably increased compared with that in the BHT101 cells, in either the absence or presence of verapamil $(\mathrm{P}<0.05)$. Therefore, $8305 \mathrm{C}$ cells were sorted and SP and MP cells were collected separately, which were termed as $8305 \mathrm{C}-\mathrm{SP}$ and $8305 \mathrm{C}-\mathrm{MP}$. Following culture for 1 week, the total protein was extracted and immunoblotting results demonstrated that protein levels of ALDH, CD44, CD133, ABCG2 and ABCB1, which are all CSC-associated markers, were markedly increased in $8305 \mathrm{C}-\mathrm{SP}$ cells compared with those in 8305C-MP cells (Fig. 1C).

Enhanced proliferation, tumorigenicity and drug resistance of SP cells compared with those of MP cells. Sorted SP and MP cells were cultured in vitro for 1 week. Proliferation was assayed using the MTT assay and the double period was calculated to measure the cell proliferation ability (Fig. 2A and B). The doubling times of $8305 \mathrm{C}-\mathrm{SP}$ and $8305 \mathrm{C}-\mathrm{MP}$ cells were $33.3 \pm 0.4$ and $56.4 \pm 1.3 \mathrm{~h}$, respectively. The doubling times of BHT101-SP and BHT101-MP cells were 34.6 \pm 0.8 and $58.5 \pm 2.7 \mathrm{~h}$, respectively. As aforementioned, a colony formation assay was performed, and colony formation efficiency was calculated. The plating efficiency of $8305 \mathrm{C}-\mathrm{SP}$ and $8305 \mathrm{C}-\mathrm{MP}$ cells was $75.3 \pm 5.5$ and $20.7 \pm 3.1 \%$. In addition, the plating efficiency of BHT101-SP cells $(87.0 \pm 4.4 \%)$ was also increased compared with that of BHT101-MP cells $(13.3 \pm 1.5 \%)$ (Fig. 2C and D). The results demonstrated that SP cells have enhanced proliferative ability.

To measure tumorigenicity, various numbers of wild-type $8305 \mathrm{C}$ cells were subcutaneously injected into a nude mouse model (Fig. 2E). At least $1 \times 10^{6} 8305 \mathrm{C}$ cells were required to make the mice bear tumor and the mean time for xenograft 


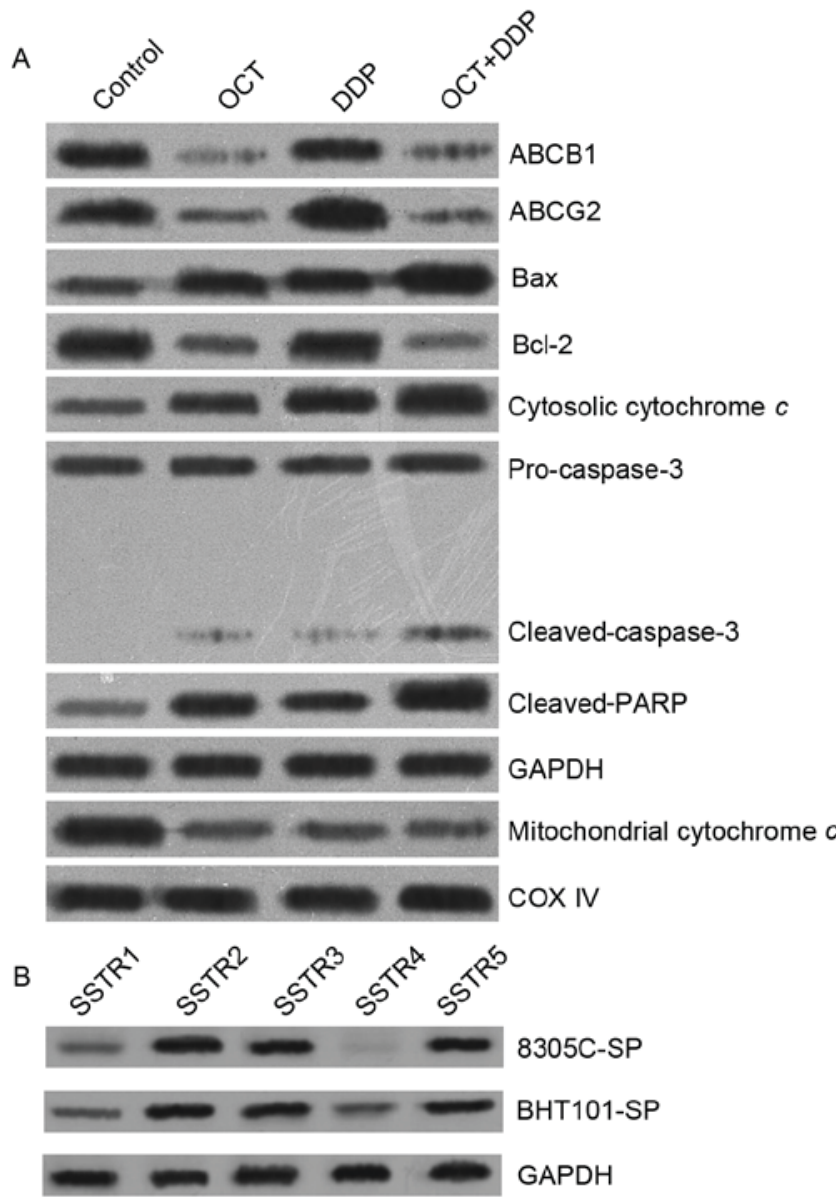

Figure 5. Associated protein expression of SP cells following combined treatment. (A) Expression of chemotherapeutic drug resistance-associated proteins and apoptosis-associated proteins following combined treatment. (B) SSTR subtypes in SP cells. SP, side population; SSTR, somatostatin receptor; OCT, octreotide; DDP, cisplatin; ABCB1, ATP-binding cassette subfamily B member 1; ABCG2, ATP-binding cassette subfamily G member 2; Bcl-2, B cell lymphoma-2; Bax, Bcl-2-associated X protein; PARP, poly(ADP-ribose) polymerase; COX IV, cytochrome $c$ oxidase subunit IV.

tumor formation was $27.3 \pm 1.5$ days. A total of $5 \times 10^{4}$ of $8305 \mathrm{C}-\mathrm{SP}$ cells was sufficient to ensure the mice bore tumors within $19.3 \pm 2.2$ days. By contrast, even if the mice were injected with $1 \times 10^{6} 8305 \mathrm{C}-\mathrm{MP}$ cells, they did not bear tumors when they were sacrificed. The results demonstrated that SP cells have enhanced in vivo tumorigenesis ability compared with MP cells.

As a chemotherapeutic agent, DDP has cytotoxicity to cancer cells; addition of DDP suppresses cancer cell proliferation. Cell viability was measured following treatment of various doses of DDP, and it was observed that DDP was more cytotoxic to MP cells compared with SP cells, and only weakly inhibited SP cell proliferation. The $\mathrm{IC}_{50}$ values of DDP to MP cells and SP cells were 4.34 and $47.83 \mu \mathrm{M}$, respectively $(\mathrm{P}<0.05)$. In conclusion, SP cells have enhanced drug resistance compared with MP cells.

Combined effect of OCT and DDP on 8305C-SP cell proliferation. An MTT proliferation assay was also performed to measure 8305 -SP cell viability at various drug concentrations. The results demonstrated that separate treatment of OCT and DDP caused cell proliferation inhibition in a dose-dependent manner (Fig. 3A and B). A low concentration of either OCT or DDP weakly suppressed $8305 \mathrm{C}-\mathrm{SP}$ cell proliferation. The $\mathrm{IC}_{50}$ of $8305 \mathrm{C}-\mathrm{SP}$ cells to OCT was $173.8 \mu \mathrm{M}$ and the $\mathrm{IC}_{50}$ to DDP was $47.83 \mu \mathrm{M}$. OCT $(10 \mu \mathrm{M})$ was selected in combination with different doses of DDP, and the $\mathrm{IC}_{50}$ to DDP decreased to $10.44 \mu \mathrm{M}$ (Fig. 3C). Furthermore, DDP $(5 \mu \mathrm{M})$ in combination with various doses of OCT was selected, and the $\mathrm{IC}_{50}$ to OCT decreased to $54.58 \mu \mathrm{M}$ (Fig. 3D). OTC and DDP exhibited additive effects, which were evaluated by isobologram analysis (Fig. 3E). The combination of OTC and DDP exerted synergistic effects on the inhibition of 8305-SP cell proliferation.

The doses of OCT and DDP used in vivo in the present study were selected according to previous studies $(25,26)$. OCT was injected at a dose of $100 \mu \mathrm{g} / \mathrm{kg}$ every day for 10 days. DDP was injected at a dose of $5 \mathrm{mg} / \mathrm{kg}$ every week for 4 weeks. The volume and weight of each tumor mass is presented in Fig. 3F and G. The OCT single treatment was ineffective, whereas the DDP single treatment was able to inhibit tumor growth. The OCT combined DDP treatment significantly suppressed tumor growth $(\mathrm{P}<0.05)$. These results indicate that combination treatment of OCT and DDP inhibits $8305 \mathrm{C}-\mathrm{SP}$ cell proliferation synergistically in vivo.

Combined effect of OCT and DDP on 8305C-SP cell apoptosis. OCT and DDP were cytotoxic to $8305 \mathrm{C}-\mathrm{SP}$ cells and inhibited cell proliferation. An Annexin V-FITC Apoptosis Detection kit was used to evaluate the proportion of apoptotic cells (Fig. 4A and B). A low concentration OCT $(10 \mu \mathrm{M})$ or DDP $(5 \mu \mathrm{M})$ barely induced the apoptosis of $8305 \mathrm{C}-\mathrm{SP}$ cells, whereas a high concentration of OCT $(40 \mu \mathrm{M})$ or DDP $(20 \mu \mathrm{M})$ was able to induce the apoptosis of $8305 \mathrm{C}-\mathrm{SP}$ cells. Combined treatment of OCT $(10 \mu \mathrm{M})$ and DTT $(5 \mu \mathrm{M})$ increased the proportion of apoptotic cells compared with the single treatment. Furthermore, combined high concentration treatment of OCT $(40 \mu \mathrm{M})$ and DTT $(20 \mu \mathrm{M})$ induced a high proportion of late-stage apoptotic cells.

Associated protein expression of SP cells treated with $O C T$ and $D D P$. The expression of a number of associated proteins was detected following combined treatment of OCT and DDP (Fig. 5). Treatment suppressed the expression of chemo-drug resistance-associated proteins, including $\mathrm{ABCB} 1$ and $\mathrm{ABCG} 2$, increased the expression of pro-apoptosis-associated proteins, including Bcl-2-associated X protein, and decreased the expression of anti-apoptosis-associated proteins, including Bcl-2. Furthermore, levels of mitochondrial cytochrome $c$ decreased and cytoplasmic cytochrome $c$ increased following combined treatment. The caspase-3 activation fragments and poly(ADP-ribose) polymerase proteolysis fragment were increased following treatment. Somatostatin receptor (SSTR) expression was detected in BHT101-SP and 8305C-SP cells, and the levels of SSTR2, SSTR3 and SSTR5 were increased compared with those of the other two subtypes (SSTR1 and SSTR4).

\section{Discussion}

DDP is one of the most commonly used chemotherapeutic agents for the treatment of numerous aggressive carcinomas, including stomach cancer, liver cancer and ATC (27-29). However, DDP treatment for ATC is usually ineffective due 
to drug resistance. Currently, the possible DDP resistance mechanisms include enhanced repair of DNA damage, a decrease in cellular drug concentration and inhibition of cell apoptosis.

The ABC transporter superfamily belongs to multiple resistance proteins. $\mathrm{ABCB} 1$ and $\mathrm{ABCG} 2$ are the family members of $\mathrm{ABC}$ transporter proteins that are important for absorption and distribution of chemotherapeutic drugs. These proteins are able to regulate the cellular drug concentration resulting in chemotherapy resistance, including resistance to DDP (30). However, DDP is not the direct substrate of ABCB1 or ABCG2, which means they are unable to pump DDP out of the cancer cell. DPP appears to cause cancer cell apoptosis induced by caspase- 3 activation, which can be inhibited by ABCB1 and ABCG2 (31,32). By contrast, DPP treatment increases ABCG2 expression leading to multidrug resistance (MDR) through activating ataxia telangiectasia-mutated/nuclear factor- $x \mathrm{~B}$ signaling (33). In the present study, DPP treatment increased the level of ABCG2 in 8305C-SP cells. Suppression of ABCG2 and $\mathrm{ABCB} 1$ expression may increase cancer cell sensitivity to chemotherapy $(34,35)$.

ABCB1 and ABCG2 typically have an increased expression in SP cells compared with MP cells. In the present study, 8305C-SP cells demonstrated increased ABCB1 and ABCG2 expression compared with $8305 \mathrm{C}-\mathrm{MP}$ cells, which results in 8305C-SP cell drug resistance to DDP. In addition, 8305C-SP cells expressed CD44 and ALDH and exhibited enhanced proliferative ability and tumorigenesis ability. Taken together, 8305C-SP cells have the biological characterization of CSCs, and, therefore, $8305 \mathrm{C}$-SP cells were used to investigate the effect of OCT and DDP.

Combined chemotherapy is able to effectively inhibit ATC SP cell proliferation (36), and the present study aimed to identify more effective combined chemotherapy for ATC. As a natural peptide with multiple biological functions, somatostatin is wildly expressed in the central nervous system and gastrointestinal tract (37). Somatostatin is involved in and regulates a number of physiological and pathological processes including regulation of anterior pituitary hormone secretion, inhibition of the release of numerous secondary hormones, neurotransmission and cell proliferation (38). The clinical applications of Somatostatin are limited due to its short biological half-life period (39). OCT, which is an artificially synthesized somatostatin analogue is more stable and effective to alimentary tract hemorrhage, pancreatitis, neuroendocrine tumors and acromegaly (40). Recently, OCT was revealed to suppress endocrine cancers and be effective in numerous types of solid tumor, including lung cancer, liver cancer, stomach cancer, colon cancer and pancreatic cancer (41-45). As an aggressive endocrine cancer, thyroid cancer progression is associated with hormone secretion. Others studies have revealed that somatostatin receptors (SSTR1-5) are expressed in thyroid cancer, and, therefore, somatostatin and the somatostatin analogue OCT may be potential chemotherapeutic agents for thyroid cancer $(46,47)$. OCT has been identified to have proliferation inhibition to medullary thyroid cancer cell lines FTC133, FTC236 and FTC238. In addition, OCT may help to improve chemotherapy sensitivity of DDP-resistant cells in combination with DDP; this combination enhances the effect of chemotherapeutic drugs $(48,49)$.
In the present study, treatment with OCT in combination with DDP suppressed the expression of ABCB1 and ABCG2 in $8305 \mathrm{C}-\mathrm{SP}$ cells, and this result demonstrated that OCT treatment inhibits the expression of $\mathrm{ABCB} 1$ and $\mathrm{ABCG} 2$ induced by DDP. Treatment of OCT in combination with DDP also activated mitochondrial apoptotic signaling, induced caspase-3 activation and further induced cell apoptosis in 8305C-SP cells. Taken together, ABCB1 and ABCG2 overexpression induced by DDP treatment suppresses cancer cell apoptosis, which can be antagonized by the treatment of OCT.

SSTRs include five subtypes, SSTR1-5, which each have distinct biological functions and different affinity to ligand. Different types of cells may express different SSTRs, and different SSTR expression leads to different biological effects in response to somatostatin and somatostatin analogues (50). The present study revealed that SSTR2, 3 and 5 subtypes exhibited increased expression in SP cells compared with MP cells, whereas another study revealed that OCT exhibited high affinity for SSTR2 (50). Therefore, it was speculated that OCT may activate signaling through interaction with SSTR2, which requires further studies to validate this hypothesis.

The results of the present study demonstrated that combined chemotherapy of OCT with DDP has good prospects. The present study is the theoretical basis for further combined chemotherapy clinical applications.

\section{Acknowledgements}

Not applicable.

\section{Funding}

The present study was funded by National Natural Science Foundation of China (grant nos. 81702422 and 81372642), Project of Jiangsu Provincial Commission of Education (grant no. 17KJB320024), Project of Jiangsu Provincial Commission of Health and Family Planning (grant no. H2017086), China Postdoctoral Science Foundation, Postdoctoral Science Foundation of Jiangsu Province, Science and Technology Program of Yancheng (grant no. YK2016044), Project of Jiangsu Provincial Health Vocational and Technical Education (grant no. J201606) and the Health Science and Technology Project of National Health and Family Planning Commission of Shanghai Pudong New Area (grant no. PW2014B-13). The funders had no role in study design, data collection and analysis, decision to publish, or preparation of the manuscript.

\section{Availability of data and materials}

The datasets used or analyzed during the present study are available from the corresponding author on reasonable request.

\section{Authors' contributions}

ZL performed experiments and wrote the manuscript. XJ and PC helped to perform experiments. XW performed statistical analysis. AD provided most reagents. YQ designed this study and wrote this manuscript. 


\section{Ethics approval and consent to participate}

All animal experiments were approved and conducted by the Institutional Animal Care and Use Committee of The Seventh People's Hospital of Shanghai (Shanghai, China).

\section{Consent for publication}

Consent for publication was obtained from patients.

\section{Competing interests}

The authors declared no competing interests.

\section{References}

1. Hundahl SA, Fleming ID, Fremgen AM and Menck HR: A national cancer data base report on 53,856 cases of thyroid carcinoma treated in the U.S., 1985-1995. Cancer 83: 2638-2648, 1998.

2. Chiacchio S, Lorenzoni A, Boni G, Rubello D, Elisei R and Mariani G: Anaplastic thyroid cancer: Prevalence, diagnosis and treatment. Minerva Endocrinol 33: 341-357, 2008.

3. Paunovic IR, Sipetic SB, Zoric GV, Diklic AD, Savic DV, Marinkovic J and Zivaljevic VR: Survival and prognostic factors of anaplastic thyroid carcinoma. Acta Chir Belg 115: 62-67, 2015

4. Are C and Shaha AR: Anaplastic thyroid carcinoma: Biology, pathogenesis, prognostic factors, and treatment approaches. Ann Surg Oncol 13: 453-464, 2006.

5. Tanaka K, Sugitani I and Fujimoto Y: A novel chemo-radiotherapy with low-dose daily cisplatin, 5-fluorouracil and doxorubicin for anaplastic thyroid carcinoma: A preliminary report. Jpn J Clin Oncol 41: 1074-1078, 2011.

6. Jing C, Gao Z, Wang R, Yang Z, Shi B and Hou P: Lenvatinib enhances the antitumor effects of paclitaxel in anaplastic thyroid cancer. Am J Cancer Res 7: 903-912, 2017.

7. Stege A, Priebsch A, Nieth C and Lage H: Stable and complete overcoming of MDR1/P-glycoprotein-mediated multidrug resistance in human gastric carcinoma cells by RNA interference. Cancer Gene Ther 11: 699-706, 2004.

8. Monden N, Abe S, Hishikawa Y, Yoshimura H, Kinugasa S, Dhar DK, Tachibana M and Nagasue N: The role of P-glycoprotein in human gastric cancer xenografts in response to chemotherapy. Int J Surg Investig 1: 3-10, 1999.

9. Prieto-Vila M, Takahashi RU, Usuba W, Kohama I and Ochiya T: Drug resistance driven by cancer stem cells and their niche. Int $J$ Mol Sci 18: E2574, 2017.

10. Zito G, Richiusa P, Bommarito A, Carissimi E, Russo L, Coppola A, Zerilli M, Rodolico V,Criscimanna A, Amato M, et al: In vitro identification and characterization of CD133(pos) cancer stem-like cells in anaplastic thyroid carcinoma cell lines. PLoS One 3: e3544, 2008.

11. Heiden KB, Williamson AJ, Doscas ME, Ye J, Wang Y, Liu D, Xing M, Prinz RA and Xu X: The sonic hedgehog signaling pathway maintains the cancer stem cell self-renewal of anaplastic thyroid cancer by inducing snail expression. J Clin Endocrinol Metab 99: E2178-E2187, 2014.

12. Carina V, Zito G, Pizzolanti G, Richiusa P, Criscimanna A, Rodolico V, Tomasello L, Pitrone M, Arancio W and Giordano C: Multiple pluripotent stem cell markers in human anaplastic thyroid cancer: The putative upstream role of SOX2. Thyroid 23: 829-837, 2013

13. Yun JY, Kim YA, Choe JY, Min H, Lee KS, Jung Y, Oh S and Kim JE: Expression of cancer stem cell markers is more frequent in anaplastic thyroid carcinoma compared to papillary thyroid carcinoma and is related to adverse clinical outcome. J Clin Pathol 67: 125-133, 2014

14. Jung CW, Han KH, Seol H, Park S, Koh JS, Lee SS, Kim MJ, Choi IJ and Myung JK: Expression of cancer stem cell markers and epithelial-mesenchymal transition-related factors in anaplastic thyroid carcinoma. Int J Clin Exp Pathol 8: 560-568, 2015.

15. Goodell MA: Stem cell identification and sorting using the Hoechst 33342 side population (SP). Curr Protoc Cytom Chapter 9: Unit9.18, 2005.
16. Zhou S, Schuetz JD, Bunting KD, Colapietro AM, Sampath J, Morris JJ, Lagutina I, Grosveld GC, Osawa M, Nakauchi H and Sorrentino BP: The ABC transporter Bcrp1/ABCG2 is expressed in a wide variety of stem cells and is a molecular determinant of the side-population phenotype. Nat Med 7: 1028-1034, 2001.

17. Wang M, Wang Y and Zhong J: Side population cells and drug resistance in breast cancer. Mol Med Rep 11: 4297-4302, 2015.

18. Yang Y, Fan Y, Qi Y, Liu D, Wu K, Wen F and Zhao S: Side population cells separated from A549 lung cancer cell line possess cancer stem cell-like properties and inhibition of autophagy potentiates the cytotoxic effect of cisplatin. Oncol Rep 34: 929-935, 2015

19. Fukaya R, Ohta S, Yamaguchi M, Fujii H, Kawakami Y, Kawase $\mathrm{T}$ and Toda M: Isolation of cancer stem-like cells from a side population of a human glioblastoma cell line, SK-MG-1. Cancer Lett 291: 150-157, 2010.

20. Hou GX, Liu PP, Zhang S, Yang M, Liao J, Yang J, Hu Y, Jiang WQ, Wen S and Huang P: Elimination of stem-like cancer cell side-population by auranofin through modulation of ROS and glycolysis. Cell Death Dis 9: 89, 2018.

21. Xie ZY, Lv K, Xiong Y and Guo WH: ABCG2-meditated multidrug resistance and tumor-initiating capacity of side population cells from colon cancer. Oncol Res Treat 37: 666-668, 670-672, 2014.

22. Pályi I, Péter I, Daubner D, Vincze B and Lõrincz I: Establishment, characterization and drug sensitivity of a new anaplastic thyroid carcinoma cell line (BHT-101). Virchows Arch B Cell Pathol Incl Mol Pathol 63: 263-269, 1993.

23. Ito T, Seyama T, Hayashi Y, Hayashi T, Dohi K, Mizuno T, Iwamoto $\mathrm{K}$, Tsuyama $\mathrm{N}$, Nakamura $\mathrm{N}$ and Akiyama $\mathrm{M}$ : Establishment of 2 human thyroid-carcinoma cell-lines (8305C, $8505 \mathrm{C}$ ) bearing p53 gene-mutations. Int J Oncol 4: 583-586, 1994.

24. Steel GG and Peckham MJ: Exploitable mechanisms in combined radiotherapy-chemotherapy: The concept of additivity. Int J Radiat Oncol Biol Phys 5: 85-91, 1979.

25. Wang M, Shan F, Zou Y, Sun X, Zhang ZR, Fu Y and Gong T: Pharmacokinetic and pharmacodynamic study of a phospholipid-based phase separation gel for once a month administration of octreotide. J Control Release 230: 45-56, 2016.

26. Kumer J, Arbitrario J, Jones J, Henjarappa N, Hoch U, Silverman J, Howlett A and Scatena C: SNS-595 potentiates the in vivo antitumor activity of carboplatin, cisplatin, and gemcitabine in solid tumor xenografts. Molecular Cancer Therapeutics 6: 3523S, 2007.

27. Derbel O, Limem S, Ségura-Ferlay C, Lifante JC, Carrie C, Peix JL, Borson-Chazot F, Bournaud C, Droz JP and de la Fouchardière $C$ : Results of combined treatment of anaplastic thyroid carcinoma (ATC). BMC Cancer 11: 469, 2011.

28. Seto A, Sugitani I, Toda K, Kawabata K, Takahashi S and Saotome T: Chemotherapy for anaplastic thyroid cancer using docetaxel and cisplatin: Report of eight cases. Surg Today 45: 221-226, 2015.

29. Zhang Y, Yang WQ, Zhu H, Qian YY, Zhou L, Ren YJ, Ren XC, Zhang L, Liu XP, Liu CG, et al: Regulation of autophagy by miR-30d impacts sensitivity of anaplastic thyroid carcinoma to cisplatin. Biochem Pharmacol 87: 562-570, 2014

30. Zhao L, Ren Y, Tang H, Wang W, He Q, Sun J, Zhou X and Wang A: Deregulation of miR-222-ABCG2 regulatory module in tongue squamous cell carcinoma contributes to chemoresistance and enhanced metastatic potential. Oncotarget 6: 44538-44550, 2015.

31. Gibalová L, Sereš M, Rusnák A, Ditte P, Labudová M, Uhrík B, Pastorek J, Sedlák J, Breier A and Sulová Z: P-glycoprotein depresses cisplatin sensitivity in L1210 cells by inhibiting cisplatin-induced caspase-3 activation. Toxicol In Vitro 26: 435-444, 2012.

32. Ceckova M, Vackova Z, Radilova H, Libra A, Buncek M and Staud F: Effect of ABCG2 on cytotoxicity of platinum drugs: Interference of EGFP. Toxicol In Vitro 22: 1846-1852, 2008.

33. Ke SZ, Ni XY, Zhang YH, Wang YN, Wu B and Gao FG: Camptothecin and cisplatin upregulate ABCG2 and MRP2 expression by activating the $\mathrm{ATM} / \mathrm{NF}-\kappa \mathrm{B}$ pathway in lung cancer cells. Int J Oncol 42: 1289-1296, 2013.

34. Mayr C, Wagner A, Neureiter D, Pichler M, Jakab M, Illig R, Berr F and Kiesslich T: The green tea catechin epigallocatechin gallate induces cell cycle arrest and shows potential synergism with cisplatin in biliary tract cancer cells. BMC Complement Altern Med 15: 194, 2015. 
35. Zhou Q, Ye M, Lu Y, Zhang H, Chen Q, Huang S and Su S: Curcumin improves the tumoricidal effect of mitomycin $\mathrm{C}$ by suppressing ABCG2 expression in stem Cell-like breast cancer cells. PLoS One 10: e0136694, 2015.

36. Chen G, Nicula D, Renko K and Derwahl M: Synergistic anti-proliferative effect of metformin and sorafenib on growth of anaplastic thyroid cancer cells and their stem cells. Oncol Rep 33: 1994-2000, 2015.

37. Rai U, Thrimawithana TR, Valery $\mathrm{C}$ and Young SA: Therapeutic uses of somatostatin and its analogues: Current view and potential applications. Pharmacol Ther 152: 98-110, 2015.

38. Olias G, Viollet C, Kusserow H, Epelbaum J and Meyerhof W: Regulation and function of somatostatin receptors J Neurochem 89: 1057-1091, 2004.

39. Mazziotti G, Mosca A, Frara S, Vitale G and Giustina A: Somatostatin analogs in the treatment of neuroendocrine tumors: Current and emerging aspects. Expert Opin Pharmacother 18 $1679-1689,2017$.

40. Alghamdi AA, Jawas AM and Hart RS: Use of octreotide for the prevention of pancreatic fistula after elective pancreatic surgery: A systematic review and meta-analysis. Can J Surg 50: 459-466, 2007.

41. Macaulay VM, Smith IE, Everard MJ, Teale JD, Reubi JC and Millar JL: Experimental and clinical studies with somatostatin analogue octreotide in small cell lung cancer. Br J Cancer 64: 451-456, 1991.

42. Kouroumalis EA: Octreotide for cancer of the liver and biliary tree. Chemotherapy 47: 150-161, 2001.
43. Wang CH, Tang CW, Liu CL and Tang LP: Inhibitory effect of octreotide on gastric cancer growth via MAPK pathway. World J Gastroenterol 9: 1904-1908, 2003

44. Ayiomamitis GD, Notas G, Zaravinos A, Drygiannakis I, Georgiadou M, Sfakianaki O, Mastrodimou N, Thermos K and Kouroumalis E: Effects of octreotide and insulin on colon cancer cellular proliferation and correlation with hTERT activity. Oncoscience 30: 457-467, 2014

45. Ebert M, Friess H, Beger HG and Büchler MW: Role of octreotide in the treatment of pancreatic cancer. Digestion 55 (Suppl 1): S48-S51, 1994.

46. Reubi JC, Chayvialle JA, Franc B, Cohen R, Calmettes C and Modigliani E: Somatostatin receptors and somatostatin content in medullary thyroid carcinomas. Lab Invest 64: 567-573, 1991.

47. Ain KB, Taylor KD, Tofiq S and Venkataraman G: Somatostatin receptor subtype expression in human thyroid and thyroid carcinoma cell lines 1. J Clin Endocrinol Metab 82: 1857-1862, 1997.

48. Shen Y, Ren ML, Shi YH, Zhang YX and Cai YL: Octreotide is the favorable alternative for cisplatin resistance reversal of ovarian cancer in vitro and in nude mice in vivo. Eur J Gynaecol Oncol 33: 584-590, 2012.

49. Zhu S, Oremo JA, Li S, Zhen M, Tang Y and Du Y: Synergistic antitumor activities of docetaxel and octreotide associated with apoptotic-upregulation in castration-resistant prostate cancer. PLoS One 3: e91817, 2014.

50. Hofland LJ, Lamberts SW and Feelders RA: Role of somatostatin receptors in normal and tumoral pituitary corticotropic cells. Neuroendocrinology 92 (Suppl 1): S11-S16, 2010. 